\title{
Pre-Post Wash Wicking Behavior, Moisture Transfer, and Water Repellency of Plain, Twill and Satin Weaves
}

\author{
Usha Chowdhary* and Islam Md Rashedul \\ Central Michigan University, USA
}

*Corresponding author: Usha Chowdhary, Professor, Department of Human Environmental Studies, Fashion Merchandising and Design, Central Michigan University, USA.

Received Date: April 02, 2019

Published Date: April 24, 2019

\begin{abstract}
The study examined moisture management behavior of plain, twill and satin weaves for $100 \%$ cotton. The intention was to bridge the gap in previous literature examined for the reported study. Increase in health consciousness and fitness have increased demand for considering moisture management research as we design apparel in the last twenty years. Consumer has begun to value these attributes due to enhanced expectations of the textile and apparel consumers. Standardized tests from ASTM and AATCC were performed to collect data. Date were analyzed using Analysis of Variance (ANOVA) and t-test analysis. Confidence level of $95 \%$ was established to test the hypotheses. The results revealed that three weaves differed for their wicking behavior, moisture transfer and water repellency significantly. The findings could be explained based on several structural attributes. Some findings were consistent with the existing literature and others were incongruent. Extension of work for future potential and viability are discussed.
\end{abstract}

\section{Introduction}

Consumer values comfort in apparel and it can be determined by performance attributes such as horizontal wicking, moisture transfer, vertical wicking, and water repellency. Some work is published for the wicking behavior within the context of moisture management. Previous research studies compared different fiber content [1,2], direction [3,4], size of floats [5], different types of weaves [6,7], count, weight and porosity of fabric [8], texturizing of yarns [9], yarn size [10], and yarn type [11]. Moisture transfer and water repellency also impact body comfort. However, many studies were not found for them in literature. One study noted that water repellency of adding dendrimer to fluorocarbon remained the same [12]. Another investigation reported that adding mixed sol to nylon enhances its water and oil repellency [13]. Therefore, they were included for this study.

Fabrics act differently before and after washing. All apparel goes through washing or dry cleaning for refurbishing. Several previous studies looked at the impact of washing on dimensional stability. However, very limited work is done for the wicking behavior $[14,15]$. Both of these studies investigated knitted fabrics.

None of the previous literature compared plain, twill and satin weaves. Because these are three basic weaves that are used to create other weaves, it was deemed important to examine their performance based on selected structural attributes. Impact of structural attributes was also reported in a limited manner.

\section{Literature Review}

Findings from the previous studies are reported to justify the developed hypotheses. One of the studies examined the wicking of Nylon 6.6 continuous and textured yarns. The authors found that tension applied to the twist impacted wicking significantly. Pore size and shape also had effect on wicking behavior [1]. Kundu SK, et al. [2] found that cotton and spandex blend had higher wicking rate than polyester/spandex and rayon/spandex. Another study reported that vertical wicking was higher in weft direction than warp direction [3]. They stressed to importance of fiber to fiber action as microcapillary and between yarn to yarn as microcapillary action. A team of scholars examined vertical wicking for cotton fabric and found that wicking rate was higher in weft than warp direction because number of yarns were more in the weft direction [4]. They recommended further research before generalizing any findings. Increase in percentage of floats and arcs increased the wicking behavior [5].

A previous study that examined the same three weaves as used in the reported study but in different fiber contents found that warp cotton and weft polyester showed higher wicking height in 
warp of plain, twill and satin weaves [6]. Satin weave had higher wicking height in weft direction than twill and plain weaves. When both warp and weft were polyester, wicking rate was lower than the polyester blend. In their study, wicking increased from 5 minutes to 20 minutes. When warp was cotton and weft was polyester, higher wicking happened in warp because cotton has higher affinity to water. When warp was polyester and weft was cotton, higher wicking happened in the weft direction. When both warp and weft were polyester or poly/cotton blend, it showed higher absorption in twill and plain weaves. Parveen BK, et al. [7] used mercerized cotton and found that satin weave had higher wicking than twill and plain weaves. They attributed it to the longer floats. Another study reported on the impact of conventional and ring spun yarns on the wicking behavior of fabrics. Ring spun yarns performed better than the compact yarns [8]. Fabrics wicked similar to yarns. Mean for compact yarns was $3.99-4.35 \mathrm{~mm}$ and that for ring yarns was $6.99 \mathrm{~mm}$ after 20 minutes.

Another scholar found that change in fabric count, weight and porosity impacted the wicking ability of knitted fabrics. Increase in course density wicking increased and so was true for increase in porosity for vertical wicking [9]. A study of wicking of polyester unveiled that vertical wicking was influenced by the process to texturizing the yarn and fabric density in the weft direction [10]. The study did not find conclusive results for the weave type. However, texturized yarn had higher wicking rates than the filament yarns. Increase in number of yarns in crosswise direction, wicking height increased for 5-15 minutes and then stabilized. Moisture management study of profiled fabrics revealed that Viscose Outlast $₫$ provided the best wicking but low drying ability [11]. Coolmax ${ }^{\circledR}$ had good wicking and drying ability. Moisture management was weaker for coarser than finer fabrics. Increase in density resulted in increased thickness $[3,11]$.

Adding dendrimer to fluorocarbon allowed same level of water repellency with less curing requirements [12]. Adding mixed solution to nylon was examined for its impact on water repellency [13]. Couple other studies examined the impact of laundering on wicking behavior of knitted fabrics and found that wicking improved between 5 and 25 study in one study and first to fifth wash in the other study $[14,15]$. Another study claimed that adding cotton to polyester increased dimensional instability of the fabric in both warp and weft directions. However, it was higher in widthwise than lengthwise direction [16]. Researchers examined that impact of physical factors on dimensional stability of cotton after repeated laundering. Several researchers purported that repeated laundering cycles increase shrinkage as well as fabric count, weight, thickness and cover factor $[14,15,17]$. One of the studies reported that the most change occurred until the fourth laundering $[17,18]$ and another study noticed change beyond the fifth laundering for the knitted t-shirts [14]. Changes in weight, count and thickness can impact number of pores in a fabric and thus influence the wicking ability, wettability and moisture transfer of the fabric.

Based on the preceding literature review, following six hypotheses were developed.

\section{Hypotheses}

Based on the literature review, the following seven hypotheses were developed.

Hypothesis 1: Three weaves will differ for horizontal wicking, moisture transfer, vertical- wicking, and water repellency in unwashed and washed forms.

Hypothesis 2: No difference will exist between three weaves for fabric thickness in washed and unwashed forms.

Hypothesis 3: Bleached and unbleached cotton in plain weave will differ for horizontal wicking, moisture transfer, vertical wicking, and water repellency in unwashed and washed forms.

Hypothesis 4: High count bleached plain weave and satin weave will differ for horizontal wicking, moisture transfer, vertical wicking, and water repellency for washed and unwashed forms.

Hypothesis 5: Yarn size will impact horizontal and vertical wicking in washed and unwashed forms.

Hypothesis 6: Satin weave will have higher wicking than the plain and twill weaves due to longer floats.

Hypothesis 7: Fabric with plied yarns will have lower wicking than the single spun yarns.

\section{Materials and Methods}

This section defines attributes (Table 1), provides standards (Table 2), and describes methods used for this investigation. To establish common understanding, Table 2 provides information on the methods used to perform various tests for data collection. Table 2 also provide source for those tests, as well as number and size of specimens so that future researchers can replicate the work on other types of fabrics. Three fabrics were obtained from Cotton Incorporated. Plain cotton was received in the bleached form, and twill and satin were unbleached. To have valid comparison unbleached cotton was purchased from the local fabric store.

Table 1: Definitions of terms for the investigation.

\begin{tabular}{|c|c|}
\hline Textile Attribute & Definition \\
\hline Fabric Count & Number of warp and weft yarns per inch \\
\hline Fabric Thickness & $\begin{array}{c}\text { Distance between two planes of the fabric mea- } \\
\text { sured in millimeters }\end{array}$ \\
\hline Fabric Weight & Grams per square meter (GSM) \\
\hline Horizontal Wicking & $\begin{array}{l}\text { Spread of water in warp and weft directions } \\
\text { measured in square millimeter per second. }\end{array}$ \\
\hline Moisture Transfer & $\begin{array}{l}\text { Absorption of water in seconds on a fabric fixed } \\
\text { in an embroidery hoop. }\end{array}$ \\
\hline Vertical Wicking & Lengthwise wicking of water in five minutes. \\
\hline Water Repellency & $\begin{array}{c}\text { Wettability pattern of fabric formed after } \\
\text { spraying } 250 \text { cc of water on a taut fabric in an } \\
\text { embroidered frame. }\end{array}$ \\
\hline Yarn Size & Weight of 1000 meters of yarn in grams. \\
\hline Yarn Type & $\begin{array}{l}\text { To determine if yarn is created by twisting } \\
\text { fibers, single yarns or plied yarns. }\end{array}$ \\
\hline
\end{tabular}


Table 2: Textile attribute, source and number of specimens \& size.

\begin{tabular}{|c|c|c|}
\hline Attribute & Test \# / Source & $\#$ and Size of Specimens \\
\hline Fabric Count & ASTM D $3775-2017^{18}$ & $5 /\left(1 " x 1^{\prime \prime}\right)$ \\
\hline Fabric Thickness & ASTM D-1777 - 2015 18 & $10 / \mathrm{NA}^{4}$ \\
\hline Fabric Weight & ASTM D-3776 - $2002^{18}$ & $5 / 5 " x 5^{\prime \prime}$ \\
\hline Yarn Type & Chowdhary \& Wroblewski, $2016^{19}$ & 5/NA \\
\hline Yarn Size & Chowdhary \& Wroblewski, $2016^{1}$ & $10 / 1$ meter $^{4}$ \\
\hline Horizontal Wicking & AATCC $198-2013^{20}$ & $5(8 " x 8 ")$ \\
\hline Moisture Transfer & AATCC $79-2014^{20}$ & $1\left(8^{\prime \prime} \times 8\right)^{\prime \prime}$ \\
\hline Vertical Wicking & AATCC $197-2013^{20}$ & $5\left(6.2^{\prime \prime} \times 1 "\right)^{2}$ \\
\hline Water Repellency & AATCC $22-2014^{2}$ & $5\left(7 " \times 7^{\prime \prime}\right)^{3}$ \\
\hline
\end{tabular}

1: Five different spots are used for five readings. 2: The standard requires three specimens. 3: The standard requires three specimens. 4. Even though the test required 10 specimens, researchers reduced to 5 observations for being consistent across various tests.

\section{Structural Attributes}

For fabric count, five places were selected across the width and number of warp and weft were counted in both washed and unwashed forms for plain, twill and satin fabrics (ASTM D 3775 -2017. They were reported using convention of warp $\mathrm{x}$ weft is equal to warp + weft (Table 3-4) for both washed and unwashed forms. Fabrics were then classified as medium (twill) and high (plain and satin)20. Means and standard deviations were computed to allow comparison for various variables using ANOVA and t-test analysis at $95 \%$ level of confidence.

Table 3: Structural attributes of plain, twill and satin weaves in unwashed cotton.

\begin{tabular}{|c|c|c|c|c|c|c|c|c|}
\hline \multirow{2}{*}{ Category } & \multicolumn{2}{|c|}{ Plain 1 Bleached } & \multicolumn{2}{|c|}{ Plain 2 Unbleached } & \multicolumn{2}{|c|}{ Twill } & \multicolumn{2}{|c|}{ Satin } \\
\hline & Mean & $\mathrm{SD}$ & Mean & $\mathrm{SD}$ & Mean & SD & Mean & SD \\
\hline \multicolumn{9}{|l|}{ Yarn Size in Tex } \\
\hline Warp & 6.5 & 0.527 & 17.2 & 0.789 & 60.8 & 1.549 & 15.7 & 0.823 \\
\hline Weft & 6.9 & 0.738 & 12.3 & 0.483 & 57.2 & 1.549 & 14.7 & 0.675 \\
\hline Classification [23] & Fine & & Medium & & Heavy & & Medium & \\
\hline \multicolumn{9}{|l|}{ Yarn Type } \\
\hline Warp & Single & & Single & & Plied & & Single & \\
\hline Weft & Single & & Single & & Plied & & Single & \\
\hline \multicolumn{9}{|l|}{ Fabric Count } \\
\hline Threads per inch & 255 & 0.7 & 166.4 & 1.1 & 113.8 & 0.8 & 239.8 & 0.8 \\
\hline Warp & 150.6 & 0.894 & 88.6 & 0.894 & 65.6 & 0.894 & 139.4 & 1.517 \\
\hline Weft & 104.4 & 1.342 & 77.8 & 0.894 & 48.2 & 0.837 & 100.4 & 1.14 \\
\hline Classification & High & & High & & High & & High & \\
\hline $\begin{array}{l}\text { Fabric Weight in } \\
\text { GSM }\end{array}$ & 81.639 & 0.78 & 108.674 & 1.801 & 286.734 & 3.613 & 154.621 & 1.702 \\
\hline Classification & Light & & Light & & Heavy & & Light & \\
\hline $\begin{array}{l}\text { Fabric Construc- } \\
\text { tion }\end{array}$ & Woven & & Woven & & Woven & & Woven & \\
\hline Repeat & $1 \times 1$ & & $1 \times 1$ & & $3 \times 1$ & & $4 \times 1$ & \\
\hline Fabric Thickness & 0.16 & 0 & 0.28 & 0 & 0.784 & 0.009 & 0.36 & 0 \\
\hline
\end{tabular}

Table 4: Structural attributes of plain, twill and satin weaves in washed form.

\begin{tabular}{|c|c|c|c|c|c|c|c|c|}
\hline \multirow{2}{*}{ Category } & \multicolumn{2}{|c|}{ Plain 1 Bleached } & \multicolumn{2}{|c|}{ Plain 2 Unbleached } & \multicolumn{2}{|c|}{ Twill } & \multicolumn{2}{|c|}{ Satin } \\
\hline & Mean & SD & Mean & SD & Mean & SD & Mean & SD \\
\hline \multicolumn{9}{|l|}{ Yarn Size in Tex } \\
\hline Warp & 6.3 & 0.483 & 16.6 & 0.516 & 56.3 & 0.823 & 13.6 & 0.516 \\
\hline Weft & 6.6 & 0.516 & 11.7 & 0.483 & 53.5 & 0.972 & 13 & 0 \\
\hline Classification & Fine & & Medium & & Heavy & & Medium & \\
\hline \multicolumn{9}{|l|}{ Yarn Type } \\
\hline Warp & Single & & Single & & Plied & & Single & \\
\hline Weft & Single & & Single & & Plied & & Single & \\
\hline
\end{tabular}




\begin{tabular}{|c|c|c|c|c|c|c|c|c|}
\hline $\begin{array}{c}\text { Fabric Count in } \\
\text { GSM }\end{array}$ & 85.62 & 1.446 & 112.866 & 2.051 & 318.99 & 2.624 & 154.857 & 0.303 \\
\hline Classification & Light & & Light & & Heavy & & Light & Woven \\
\hline $\begin{array}{c}\text { Fabric Construc- } \\
\text { tion }\end{array}$ & Woven & Woven & & $3 \times 1$ & 0.837 & $4 \times 1$ & \\
\hline Repeat & $1 \times 1$ & & $1 \times 1$ & & 0.009 & 0.448 & 0.011 \\
\hline Fabric Thickness & 0.224 & 0.009 & 0.336 & 0.009 & 0.924 & 0.009 \\
\hline
\end{tabular}

Fabric thickness was measured using ASTM D 1777-2015 using digital thickness tester. Thickness was measured at 5 places and means and standard deviation were calculated for subsequent analysis to test hypothesis related to this variable. Data are presented in tables $3 \& 4$. Fabric weight was determined by using ASTM D 3776-2002. Five specimens of 5"x5" dimensions were measured in both washed and unwashed forms. The following formula was used to calculate grams per square meter (GSM) and subsequent classification [20].

Grams per square meter $($ GSM $)=33.906 x$ Ounces Per Square Yard

Three of the four fabrics were light weight and twill was heavy weight. Next, yarn size was measured using direct method in Tex unit. Tex refers to weight in grams of 1000 meters of yarn. Researchers weighed one meter of yarn and multiplied it by 1000 to compute as Tex. Standard did not explain it specifically. Therefore, it was performed using Chowdhary U [22]. ASTM test \# D2260-03 (Reapproved 2013) offers conversion factors for changing from one system to another. The yarns were classified using Collier, et al. [23] as fine, medium and heavy.

Fabric weave and repeat were determined using linen tester [24]. All fabrics were woven fabrics. Plain weaves had $1 \times 1$ repeat. Repeat for the twill weave was $3 \times 1$ and for satin weave was $4 \times 1$. Previous researchers noted that float size can impact wicking [5]. Therefore, it was important to consider so.

\section{Performance attributes}

Horizontal Wicking used AATCC 198 - 2013 for data collection [19]. Five specimens were cut in 8"x8" dimension. One cubic centimeter water was dispensed on a framed fabric with 1 " difference between the tip of the burette and fabric surface. The dispensed water was left for five minutes and spread in length and width were measured in millimeters. Following formula was used to determine horizontal wicking in $\mathrm{mm}^{2} /$ second.

Horizontal Wicking $\mathrm{mm}^{2} / \mathrm{sec}=\frac{\pi \times 0.25 \times \text { spread in length } \times \text { spread in width }}{300}$

Mean and standard deviations were computed for appropriate comparisons to determine statistical significance at 95\% level of confidence. Information is provided in tables $3 \& 4$.

Moisture transfer was measured using AATCC 79 - 201425. Five specimens were collected from a framed fabric of 8"x8". One drop of water was dispensed from 1inch height and time taken to absorb the drop was recorded for each observation in seconds. The maximum time allowed for the experiment was 60 seconds. Means and Standard deviations were computed for each weave and used for appropriate comparisons in both washed and unwashed forms (Tables 5\&6).

Vertical wicking was tested using AATCC 197-2013 and lengthwise spread was measured in millimeters/second for both washed and unwashed specimens in three weaves. Data were collected and recorded using appropriate descriptive statistic for subsequent use in statistical analysis. Water Repellency was measured using AATCC 22-201425. Five specimens were used and $250 \mathrm{ml}$ water was sprayed on the specimen. Water pattern was compared to the replica and evaluated on at rating scale of 0-100 for each specimen in washed and unwashed forms. A minimum rating of 70 was classified as pass and below 70 as fail (Tables $5 \& 6$ ). Statistical analyses were used to test hypotheses.

Table 5: Performance attributes of plain, twill and satin weaves in unwashed form.

\begin{tabular}{|c|c|c|c|c|c|c|c|c|}
\hline \multirow{2}{*}{ Category } & \multicolumn{2}{|c|}{ Plain 1 Bleached } & \multicolumn{2}{|c|}{ Plain 2 Unbleached } & \multicolumn{2}{|c|}{ Twill } & \multicolumn{2}{|c|}{ Satin } \\
\hline & Mean & SD & Mean & SD & Mean & SD & Mean & SD \\
\hline Horizontal Wicking $\mathrm{mm}^{2} / \mathrm{sec}$ & 19.188 & 0.342 & 4.838 & 0.213 & 0.734 & 0.055 & 0.634 & 0.035 \\
\hline \multicolumn{9}{|c|}{ Vertical Wicking in mm } \\
\hline Wrap & 0.157 & 0.003 & 0.123 & 0.002 & 0.021 & 0.002 & 0.025 & 0.002 \\
\hline Weft & 0.149 & 0.001 & 0.112 & 0.003 & 0.017 & 0 & 0.021 & 0.001 \\
\hline \multirow{2}{*}{$\begin{array}{l}\text { Moisture transfer in } \\
\text { seconds }\end{array}$} & Fail & & Fail & & Fail & & Fail & \\
\hline & 9.2 & 0.447 & 52.4 & 1.36 & $60+$ & 0 & $60+$ & 0 \\
\hline \multirow[t]{2}{*}{ Water repellency } & Fail & & Pass & & Pass & & Pass & \\
\hline & 0 & 0 & 70 & 0 & 80 & 0 & 80 & 0 \\
\hline
\end{tabular}


Table 6: Performance attributes of plain, twill and satin weaves in washed form.

\begin{tabular}{|c|c|c|c|c|c|c|c|c|}
\hline \multirow{2}{*}{ Category } & \multicolumn{2}{|c|}{ Plain 1 Bleached } & \multicolumn{2}{|c|}{ Plain 2 Unbleached } & \multicolumn{2}{|c|}{ Twill } & \multicolumn{2}{|c|}{ Satin } \\
\hline & Mean & SD & Mean & SD & Mean & SD & Mean & SD \\
\hline Horizontal Wicking $\mathrm{mm} 2 / \mathrm{sec}$ & 26.495 & 0.533 & 14.585 & 0.678 & 0.875 & 0.057 & 12.366 & 0.936 \\
\hline \multicolumn{9}{|c|}{ Vertical Wicking in mm } \\
\hline Wrap & 0.191 & 0.003 & 0.158 & 0.002 & 0.025 & 0.002 & 0.129 & 0.004 \\
\hline Weft & 0.177 & 0.004 & 0.147 & 0.003 & 0.023 & 0 & 0.119 & 0.004 \\
\hline \multirow{2}{*}{$\begin{array}{c}\text { Moisture transfer in } \\
\text { seconds }\end{array}$} & Pass & & Fail & & Fail & & Fail & \\
\hline & 3.000 & 0 & 7.8 & 0.447 & $60+$ & 0 & 8.2 & 0.447 \\
\hline \multirow[t]{2}{*}{ Water repellency } & Fail & & Fail & & Pass & & Fail & \\
\hline & 0 & 0 & 0 & 0 & 80 & 0 & 0 & 0 \\
\hline
\end{tabular}

To compare unwashed with washed specimens, the fabric was laundered using AATCC Laboratory Procedure 1-2018. A large piece of fabric was washed and then cut into recommended size of specimens for testing by the standardized tests used for the study.

\section{Results and Discussion}

Results from the structural attributes revealed that bleached cotton had plain weave with fine yarn size, single spun yarn type, high count, light weight, and $1 \times 1$ repeat. Unbleached plain weave fabric had medium yarn size, single yarn, light weight and 1X1 repeat. Twill weave had heavy yarn size, plied yarn, medium count, heavy weight and $3 \times 1$ repeat. Finally, satin weave had medium yarn size, single yarn type, high count, light weight and $4 \mathrm{x} 1$ repeat. Fabric thickness was highest for twill weave followed by satin, unbleached plain, and bleached plain in both washed and unwashed forms. See tables 3\&4. It was also observed that fabric thickness was higher in washed as opposed to the unwashed form for all weaves.

\section{Performance attributes}

In general, means for beached and unbleached cotton in plain weave were higher than the twill and satin weave for horizontal wicking in both warp and weft directions in unbleached forms. This is finding is consistent with the result of previous study [8]. Bleached cotton had higher horizontal wicking than the unbleached cotton. The ratings of woven cotton for horizontal wicking were less than reported in the Technical Manual of the American Association of Textile Chemists and Colorist. Similar pattern was found for the vertical wicking.

For moisture transfer, Unbleached plain weave had higher moisture transfer than twill and stain weave in unwashed form Bleached cotton had higher moisture transfer than unbleached cotton for plain weave. Based on the standard of $<5$ seconds, only plain weave for bleached cotton passed in the washed form. However, all failed in the unwashed stage.

Results from Analysis of Variance and t-test were used to test hypothesis. Results were compared with previous research if available. For unwashed and washed forms exclusively and inclusively for three different weaves (Tables 5\&6). For water repellency, all passed except the bleached plain weave. However, in washed farm, all failed except the twill weave.

\section{Hypothesis Testing}

Based on the literature review, the following seven hypotheses were developed.

Hypothesis 1: Three weaves will differ for horizontal wicking, moisture transfer, vertical wicking, and water repellency in unwashed and washed forms.

Table 7: Washed and unwashed comparison for four performance attributes using ANOVA and t-test.

\begin{tabular}{|c|c|c|c|c|c|c|}
\hline Attribute & $\begin{array}{c}\text { U } \\
\text { Mean }\end{array}$ & $\begin{array}{c}\mathbf{U} \\
\mathrm{SD}\end{array}$ & W Mean & $\begin{array}{l}\text { W } \\
\text { SD }\end{array}$ & F -Value & t-Value \\
\hline \multicolumn{7}{|c|}{ Horizontal Wicking } \\
\hline 1 Plain & 4.838 & 0.213 & 14.585 & 0.678 & \multirow{2}{*}{$U=1730.577^{*}$} & \multirow{2}{*}{ Plain $=-27.849 *$} \\
\hline 2 Twill & 0.734 & 0.055 & 0.875 & 0.057 & & \\
\hline 3 Satin & 0.634 & 0.035 & 12.336 & 0.936 & $\mathrm{~W}=665.619^{*}$ & $\begin{array}{c}\text { Twill }=-3.615^{*} \\
\text { Satin }=-25.958^{*}\end{array}$ \\
\hline \multicolumn{7}{|c|}{ Vertical Wicking } \\
\hline Plain - W & 0.123 & 0.002 & 0.158 & 0.002 & $\begin{array}{l}\text { UW Warp }= \\
4171.667^{*}\end{array}$ & $\begin{array}{c}\text { Plain W Warp }= \\
-35.00^{*}\end{array}$ \\
\hline Twill - W & 0.021 & 0.002 & 0.025 & 0.003 & & \\
\hline
\end{tabular}




\begin{tabular}{|c|c|c|c|c|c|c|}
\hline Satin - W & 0.025 & 0.002 & 0.129 & 0.004 & $\begin{array}{l}\text { W Warp -= } \\
3056.835^{*}\end{array}$ & \\
\hline Plain - F & 0.112 & 0.003 & 0.147 & 0.003 & & Plain Filling $=--17.5^{*}$ \\
\hline Twill - F & 0.017 & 0 & 0.023 & 0 & UW weft $=4330.5^{*}$ & \\
\hline \multirow{4}{*}{ Satin - F } & \multirow{4}{*}{0.021} & \multirow{4}{*}{0.001} & \multirow{4}{*}{0.119} & \multirow{4}{*}{0.004} & \multirow{4}{*}{ W Weft $=2537.6^{*}$} & Twill Warp $=-2.0 \mathrm{~ns}$ \\
\hline & & & & & & Twill Weft = Infinity* \\
\hline & & & & & & $\begin{array}{l}\text { Satin Warp } \\
=-34.667^{*}\end{array}$ \\
\hline & & & & & & Satin Weft $=-49^{*}$ \\
\hline \multicolumn{7}{|c|}{ Moisture Transfer } \\
\hline \multirow[t]{2}{*}{ Plain } & 52.4 & 0.447 & 7.8 & 0.447 & UW1614.761* & Plain $=$ \\
\hline & & & & & & 141.139* \\
\hline Twill & 60 & 0 & 60 & 0 & W 33575.45* & Twill= \\
\hline \multirow[t]{3}{*}{ Satin } & 60 & 0 & 8.2 & 0.447 & & $0 \mathrm{~ns}$ \\
\hline & & & & & & $\mathrm{S}=231.25^{*}$ \\
\hline & & & & & & Satin $=231.25^{* *}$ \\
\hline \multirow[t]{2}{*}{$\begin{array}{l}\text { Water Repellency } \\
\text { Plain }\end{array}$} & 70 & 0 & 0 & 0 & & Plain = Infinity $*$ \\
\hline & & & & & $\mathrm{U}=$ Infinity $*$ & \\
\hline Twill & 80 & 0 & 80 & 0 & & Twill $=0$ \\
\hline Satin & 80 & 0 & 0 & 0 & & \\
\hline Twill Warp = $2 \mathrm{~ns}$ & Satin Warp $=-34.667^{*}$ & $\begin{array}{c}\text { Plain Filling }= \\
-17.5^{*}\end{array}$ & $\begin{array}{l}\text { Twill Filling = } \\
\text { Infinity* }\end{array}$ & $\begin{array}{c}\text { Satin Filling }= \\
-49.0^{*}\end{array}$ & $\mathrm{~W}=$ Infinity* & Satin = Infinity ${ }^{*}$ \\
\hline
\end{tabular}

$\mathrm{U}=$ Unwashed; $\mathrm{W}$ Washed; $\mathrm{P}=$ Plain; $\mathrm{T}=$ Twill; $\mathrm{S}=$ Satin; $\mathrm{ns}=$ not significant; ${ }^{*}$ significant at .05 level: one-tail = 1.86; two tail $=2.306$

Unwashed

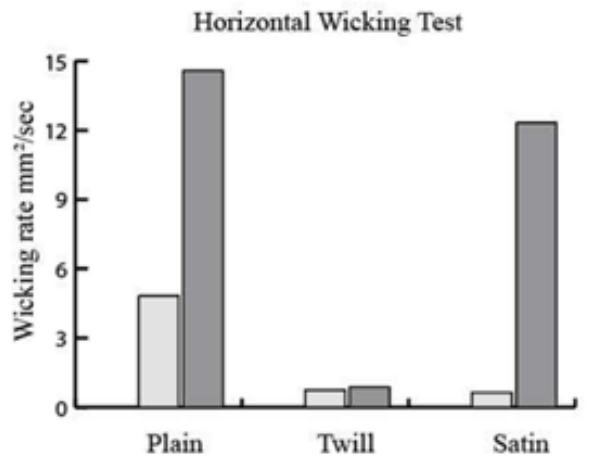

Moisture Transfer Test

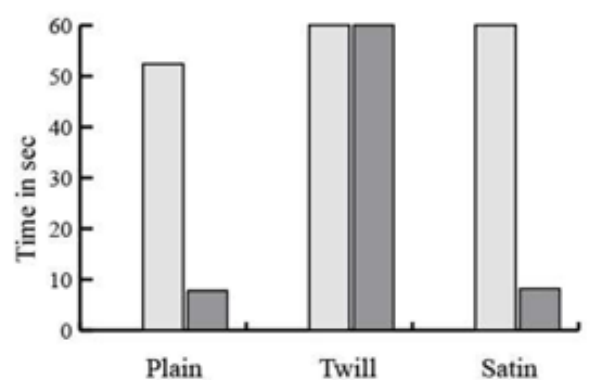

Washed

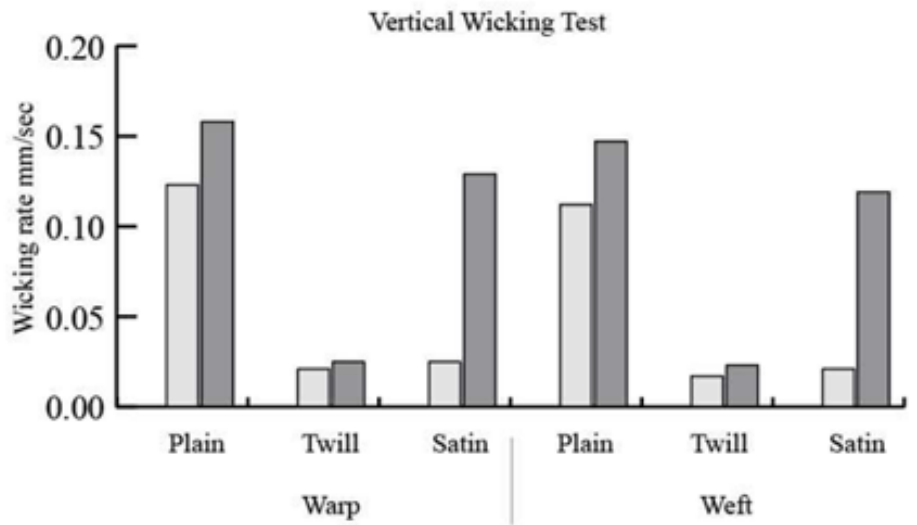

Water Repellency Test

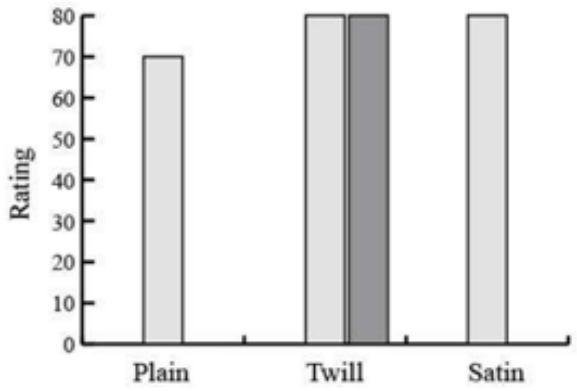

Figure 1: Pictorial Depiction of relationship between washed and unwashed forms for horizontal and vertical wicking, moisture transfer and water repellency. 
Results revealed that three weaves differed significantly (Table 7) for horizontal wicking in the unwashed form (F2, 12=1739.577. $\mathrm{p}<.05)$. So was true for the washed form (F2, $12=655.619 \mathrm{p}<.05)$. The $t$ - value of comparison between unwashed and washed forms was also significant based on the t-test for all three weaves. Table 8 shows inter weave differences and reflects that differences were significant between Plain and twill, twill and satin, and sating and plain weaves for both conditions. Except for satin pattern was similar for the vertical wicking. Moisture transfer was significantly higher for washed form than unwashed form. However, inter-weave comparisons were significant for $\mathrm{P} \times \mathrm{T}$ and $\mathrm{S} \times \mathrm{P}$ for the unwashed form and $\mathrm{P} \times \mathrm{T}$ and $\mathrm{T} \times \mathrm{S}$ for the washed form. They were not significant for $\mathrm{T} \times \mathrm{S}$ in unwashed setting and $\mathrm{S} \times \mathrm{P}$ for the washed form. For water repellency, no change was observed for twill weave. However, post-wash ratings were significantly different for water repellency. Inter weave comparison by t-test revealed that the change was not significantly different for $\mathrm{T} x \mathrm{~S}$ in unwashed form, and S x P for the washed form. Overall, Hypothesis 1 was accepted. Figure 1 shows pictorial; depiction of relations between weaves and four performance attributes.

Table 8: Washed and unwashed comparison for four performance attributes using t-tests.

\begin{tabular}{|c|c|c|c|c|c|}
\hline Attribute & $\begin{array}{c}\text { U } \\
\text { Mean }\end{array}$ & $\begin{array}{c}\text { U } \\
\text { SD }\end{array}$ & W Mean & $\begin{array}{l}\text { W } \\
\text { SD }\end{array}$ & t-Value \\
\hline \multicolumn{6}{|c|}{ Horizontal Wicking } \\
\hline 1 Plain & 4.838 & 0.213 & 14.585 & 0.678 & $\mathrm{P} \times \mathrm{T}$ \\
\hline 2 Twill & 0.734 & 0.055 & 0.875 & 0.057 & \\
\hline \multirow[t]{14}{*}{3 Satin } & 0.634 & 0.035 & 12.336 & 0.936 & $\mathrm{U}$ \\
\hline & & & & & $37.309^{*}$ \\
\hline & & & & & $\mathrm{W}$ \\
\hline & & & & & $-40.442^{*}$ \\
\hline & & & & & $\mathrm{Tx} S$ \\
\hline & & & & & $\mathrm{U}$ \\
\hline & & & & & $0.416 \mathrm{~ns}$ \\
\hline & & & & & W \\
\hline & & & & & $-24.821 *$ \\
\hline & & & & & $\mathrm{S} \times \mathrm{P}$ \\
\hline & & & & & $\mathrm{U}$ \\
\hline & & & & & $-19.245^{*}$ \\
\hline & & & & & W \\
\hline & & & & & $-4.685^{*}$ \\
\hline \multicolumn{6}{|c|}{ Vertical Wicking } \\
\hline Plain - W & 0.123 & 0.002 & 0.158 & 0.002 & Warp \\
\hline Twill - W & 0.021 & 0.002 & 0.025 & 0.003 & $\mathrm{P} \times \mathrm{T}$ \\
\hline Satin - W & 0.025 & 0.002 & 0.129 & 0.004 & U $102^{*}$ \\
\hline Plain - F & 0.112 & 0.003 & 0.147 & 0.003 & W 133* \\
\hline Twill - F & 0.017 & 0 & 0.023 & 0 & \\
\hline \multirow[t]{12}{*}{ Satin - F } & 0.021 & 0.001 & 0.119 & 0.004 & $\mathrm{~T} \times \mathrm{S}$ \\
\hline & & & & & $\mathrm{U}-4^{*}$ \\
\hline & & & & & W - $104^{*}$ \\
\hline & & & & & $\mathrm{S} \times \mathrm{P}$ \\
\hline & & & & & U- 98* \\
\hline & & & & & W 29* \\
\hline & & & & & Filling \\
\hline & & & & & $\mathrm{P} \times \mathrm{T}$ \\
\hline & & & & & U $47.5^{*}$ \\
\hline & & & & & W $124^{*}$ \\
\hline & & & & & $\mathrm{Tx} S$ \\
\hline & & & & & $\mathrm{U}-4^{*}$ \\
\hline
\end{tabular}




\begin{tabular}{|c|c|c|c|c|c|}
\hline & & & & & W -52* \\
\hline & & & & & $S \times P$ \\
\hline & & & & & U $102^{*}$ \\
\hline & & & & & W $14^{*}$ \\
\hline \multicolumn{6}{|c|}{ Moisture Transfer } \\
\hline \multirow[t]{2}{*}{ Plain } & 52.4 & 0.447 & 7.8 & 0.447 & PxT \\
\hline & & & & & U \\
\hline \multirow[t]{2}{*}{ Twill } & 60 & 0 & 60 & 0 & $-33.929 * \mathrm{~W}$ \\
\hline & & & & & $33.663^{*}$ \\
\hline \multirow[t]{7}{*}{ Satin } & 60 & 0 & 8.2 & 0.447 & \\
\hline & & & & & TxS \\
\hline & & & & & U 0 ns \\
\hline & & & & & W -33.663* \\
\hline & & & & & SxP \\
\hline & & & & & U 33.929* W 1.786 \\
\hline & & & & & ns \\
\hline \multicolumn{6}{|c|}{ Water Repellency } \\
\hline Plain & 70 & 0 & 0 & 0 & PxT \\
\hline Twill & 80 & 0 & 80 & 0 & U $\infty *$ \\
\hline \multirow[t]{7}{*}{ Satin } & 80 & 0 & 0 & 0 & W $\infty *$ \\
\hline & & & & & $\mathrm{TxS}$ \\
\hline & & & & & $\mathrm{U} 0 \mathrm{~ns}$ \\
\hline & & & & & $\mathrm{W} \infty *$ \\
\hline & & & & & SxP \\
\hline & & & & & U $\infty *$ \\
\hline & & & & & W 0 ns \\
\hline
\end{tabular}

$\mathrm{U}=$ Unwashed; $\mathrm{W}=$ Washed; $\mathrm{P}=$ Plain; $\mathrm{T}$ = Twill; $\mathrm{S}=$ Satin; $\mathrm{nS}=$ not significant; ${ }^{*}$ significant at .05 level: one-tail = 1.86; two tail = 2.306

Hypothesis 2: No difference will exist between three weaves for fabric thickness in washed and unwashed forms.

ANOVA results revealed that Laundering made cotton fabric thicker than before for all three weaves (Table 9). Inter-weave comparisons also projected the same pattern. I could be function of residue left from detergent and potential shrinkage [14,15]. Hypothesis 2 was rejected. Pictorial depiction shows that thickness increased aster washing (Figure 2).

Table 9: Comparison between plain $\mathrm{x}$ twill, twill $\mathrm{x}$ satin, and satin $\mathrm{x}$ plain in washed and unwashed forms for fabric thickness.

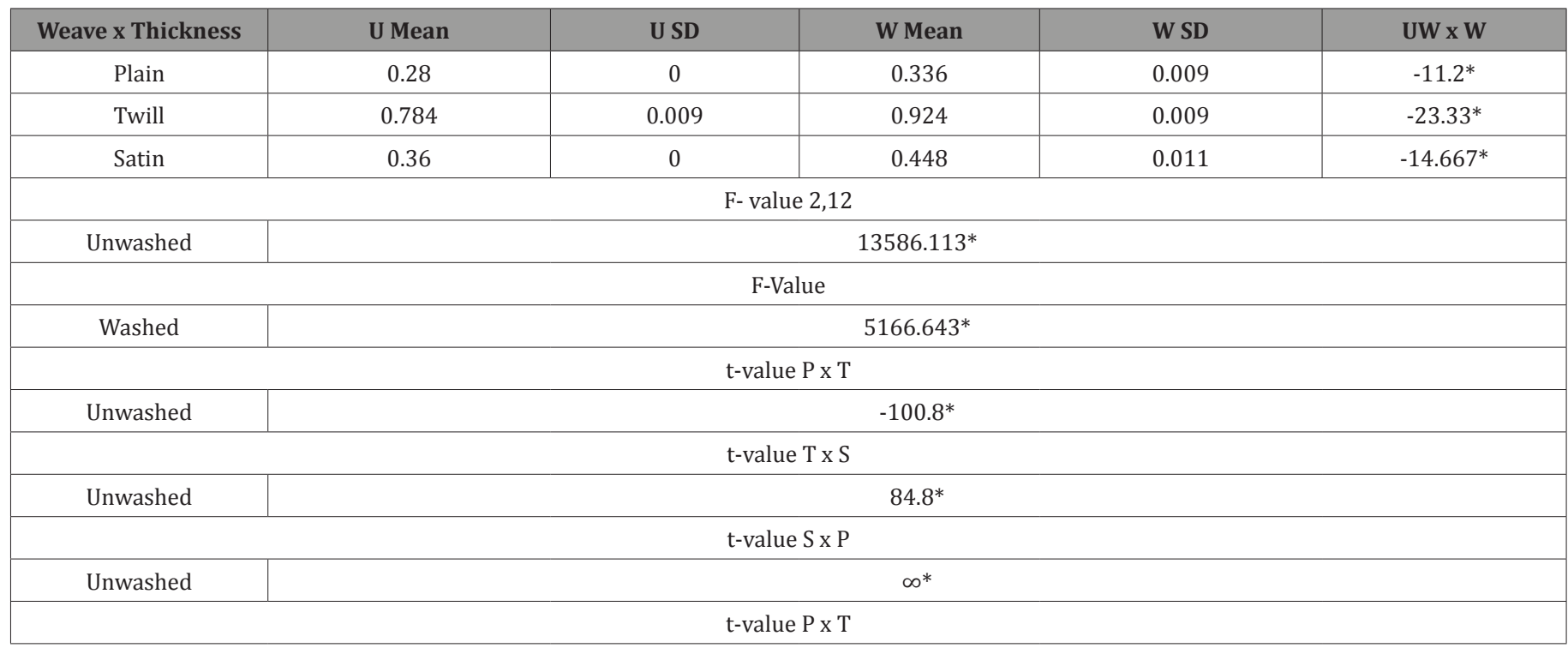




\begin{tabular}{|c|c|}
\hline Washed & \multicolumn{1}{|c|}{$-98^{*}$} \\
\hline \multicolumn{2}{|c|}{$68^{* *}$} \\
\hline Washed & t-value T x S \\
\hline \multicolumn{2}{|c|}{$16^{*}$} \\
\hline Washed & t-value S x P \\
\hline
\end{tabular}

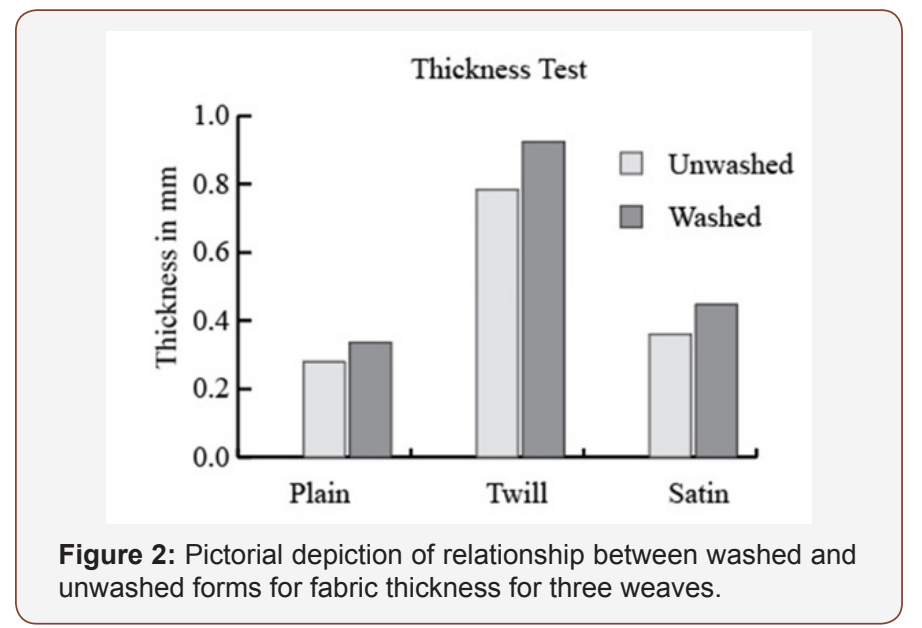

Hypothesis 3: Bleached and unbleached cotton in plain weave will differ for horizontal wicking, moisture transfer, vertical wicking, and water repellency in unwashed and washed forms.

The t-test analysis revealed that bleached cotton had better horizontal wicking, vertical wicking and moisture transfer than the unbleached cotton (Table 10). However, the unbleached cotton performed better on water repellency. When compared for washed and unwashed form, differences were significant for horizontal and vertical wicking, and as well as moisture transfer. However, differences were not significant for water repellency. Hypothesis 3 was accepted. Results makes sense because increase in moisture management is likely to have reduced water repellency. Pictorial description through Figure 3 also visually reflect so.

\section{Unwashed $\quad \square$ Washed}
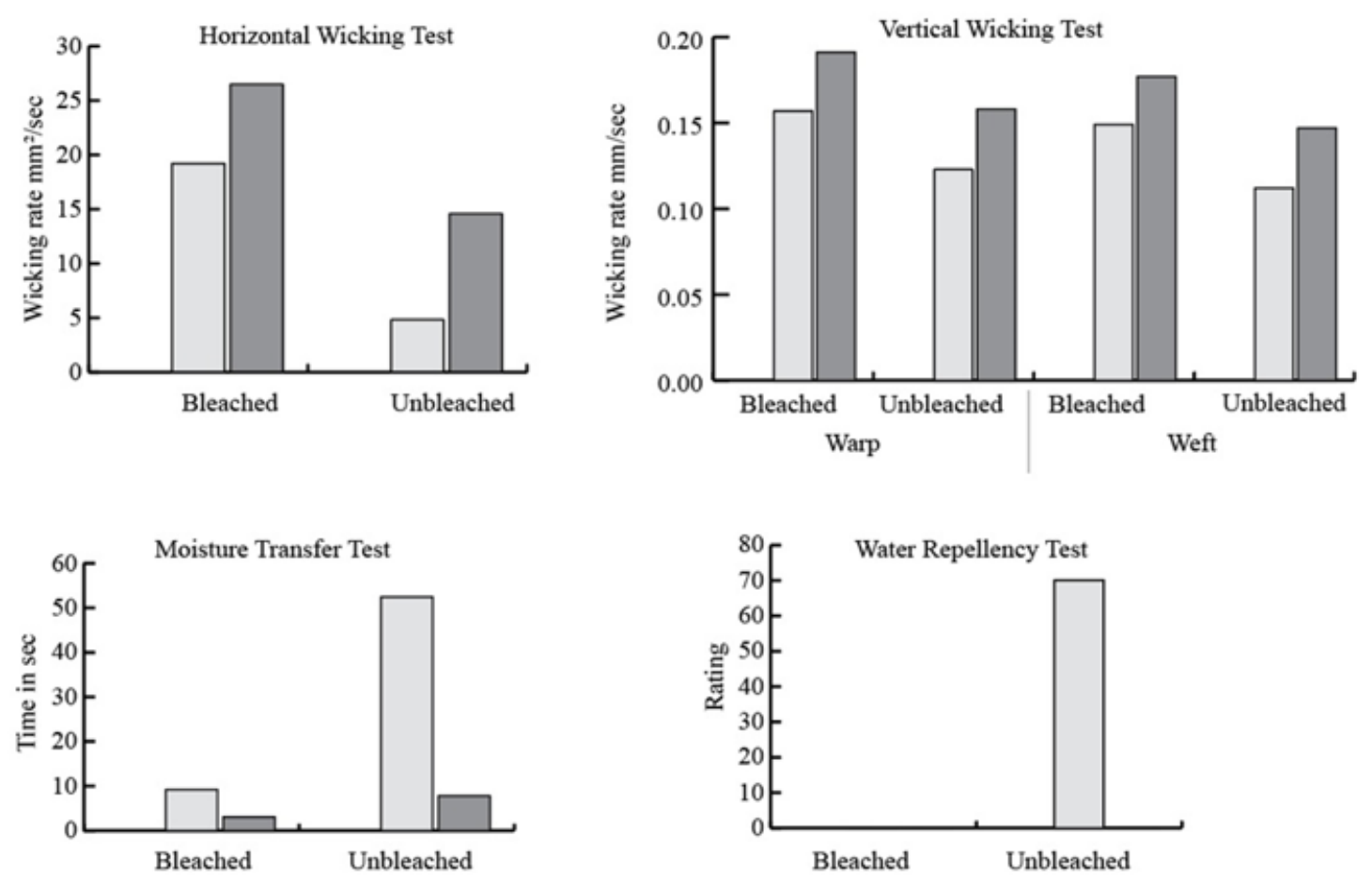

Figure 3: Pictorial depiction of relationship between bleached and unbleached plain weaves in washed and unwashed forms for four performance attributes.

Table 10: Comparison between bleached and unbleached plain weaves in washed and unwashed forms for four performance attributes.

\begin{tabular}{|c|c|c|c|c|c|c|}
\hline Attribute & \multicolumn{2}{|c|}{ Unwashed B Washed } & \multicolumn{2}{c|}{ T-Value } & t-Value \\
\hline & Mean & SD & Mean & SD & U x W W \\
\hline \multicolumn{7}{|c|}{ Horizontal Wicking } \\
\hline Bleached & 19.188 & 0.342 & 26.495 & 0.533 & 71.75 & $16.954^{*}$ \\
\hline Unbleached & 4.838 & 0.213 & 14.585 & 0.678 & & UB \\
\hline
\end{tabular}




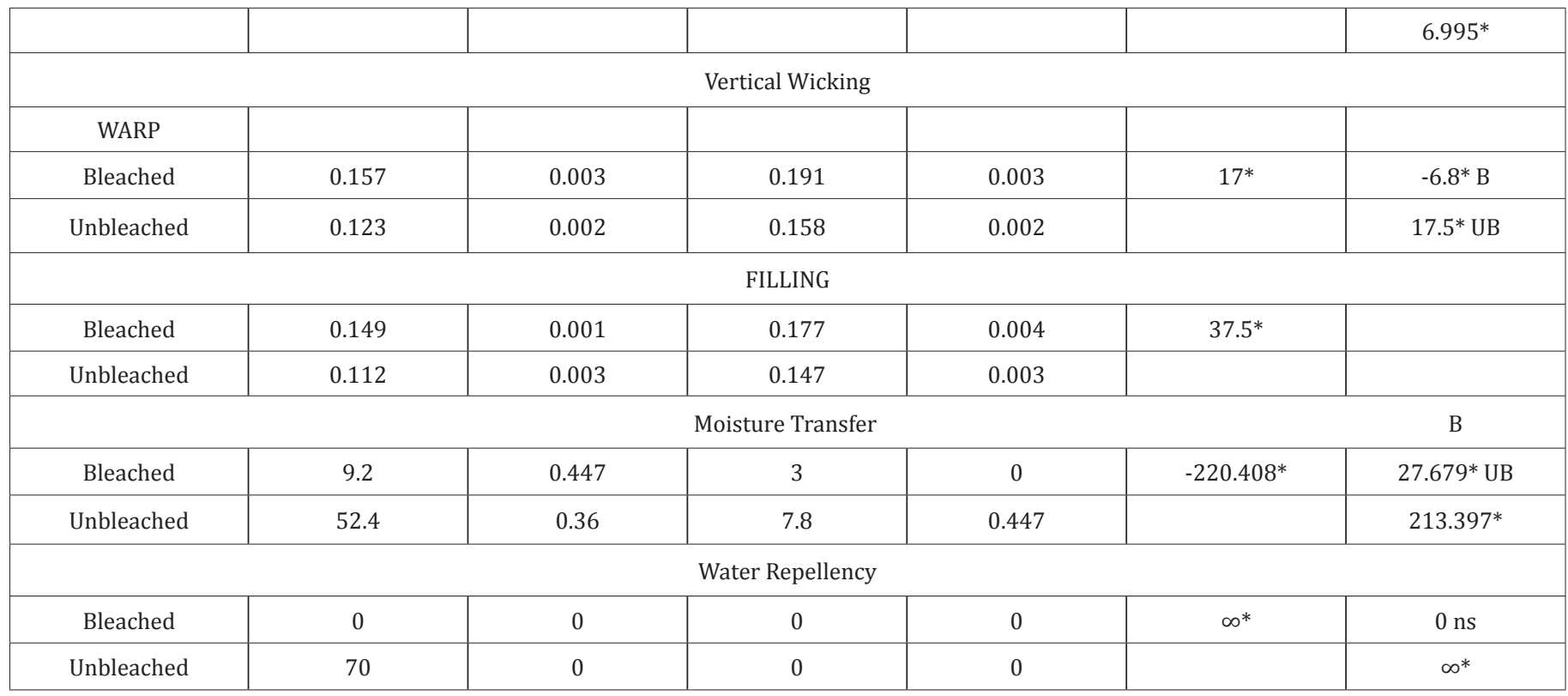

Hypothesis 4: High count bleached plain weave and satin weave will differ for horizontal wicking, moisture transfer, vertical wicking, and water repellency in washed and unwashed forms.

Based on the statistical analysis, bleached plain cotton performed better for horizontal wicking, vertical wicking and moisture transfer than satin weave (Table 11). However, satin performed better on water repellency. Hypothesis 4 was accepted. Figure 4 visually demonstrates so. This finding is inconsistent with the previous study which found that satin weave has higher wicking because of longer floats [5]. They are also different from another research study which found that satin weave had higher wicking than both plain and twill weave [7].

\section{Unwashed $\quad \square$ Washed}

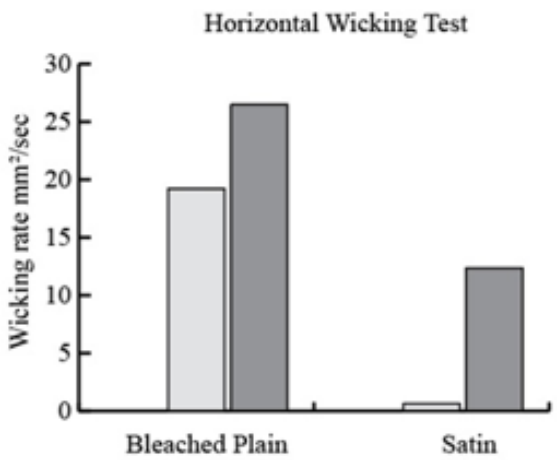

Moisture Transfer Test

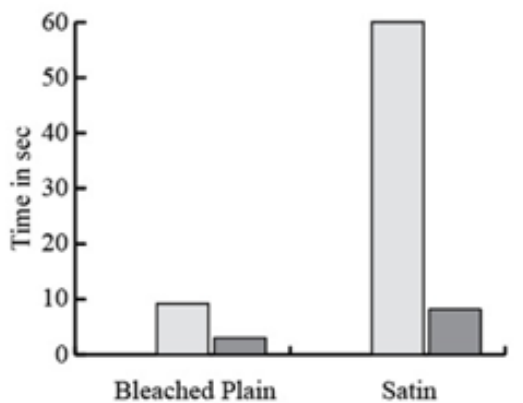

Vertical Wicking Test

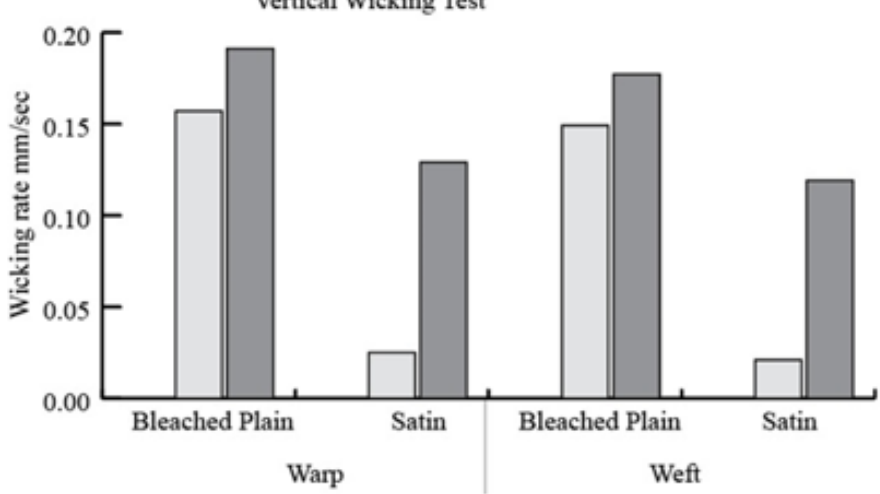

Water Repellency Test

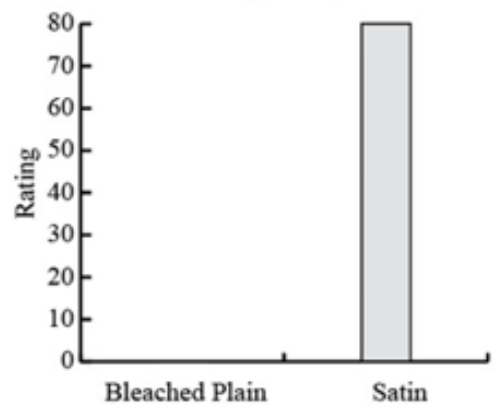

Figure 4: Pictorial depiction of relationship between washed and unwashed forms for high count bleached cotton in plain weave and unbleached satin weave for four performance attributes. 
Table 11: Comparison between high count bleached plain and unbleached satin weaves in both washed and unwashed forms for four performance attributes.

\begin{tabular}{|c|c|c|c|c|c|c|}
\hline \multirow[t]{2}{*}{ Attribute } & \multicolumn{2}{|c|}{ Unwashed } & \multicolumn{2}{|c|}{ Washed } & \multirow{2}{*}{$\begin{array}{c}\text { t-value } \\
\text { PxS }\end{array}$} & \multirow{2}{*}{$\begin{array}{c}\text { t-value } \\
\text { UxW }\end{array}$} \\
\hline & Mean & SD & Mean & SD & & \\
\hline \multicolumn{7}{|c|}{ Horizontal Wicking } \\
\hline Bleached P & 19.188 & 0.342 & 26.495 & 0.533 & P 108.503* & U -14.673* \\
\hline UB S & 0.634 & 0.035 & 12.336 & 0.936 & S - $26.515^{*}$ & W -25.004* \\
\hline \multicolumn{7}{|c|}{ Vertical Wicking } \\
\hline Bleached P warp & 0.157 & 0.003 & 0.191 & 0.003 & P -132* & $\mathrm{U}-14^{*}$ \\
\hline UB S warp & 0.025 & 0.002 & 0.129 & 0.001 & S - $30.5^{*}$ & $\mathrm{~W}-52^{*}$ \\
\hline Bleached P weft & 0.149 & 0.001 & 0.177 & 0.004 & P 64* & U -64* \\
\hline UB S weft & 0.021 & 0.001 & 0.119 & 0.004 & S 19.33 & $\mathrm{~W}-49^{*}$ \\
\hline \multicolumn{7}{|c|}{ Moisture Transfer } \\
\hline Bleached P & 9.2 & 0.447 & 3 & 0 & P 226.786* & $U-27.679 *$ \\
\hline UB S & 60 & 0 & 8.2 & 0.447 & S 23.214* & W 231.25* \\
\hline \multicolumn{7}{|c|}{ Water Repellency } \\
\hline Bleached P & 0 & 0 & 0 & 0 & $\mathrm{P} \infty *$ & U $0 \mathrm{~ns}$ \\
\hline UB S & 80 & 0 & 0 & 0 & S $0 \mathrm{~ns}$ & $\mathrm{~W} \infty *$ \\
\hline
\end{tabular}

$\mathrm{U}=$ Unwashed; $\mathrm{W}=$ Washed; $\mathrm{P}=$ Plain; $\mathrm{S}=$ Satin; $\mathrm{UB}=$ Unbleached; $\mathrm{ns}=$ not significant

*significant at 0.05 level; one-tail $=1.86$; two-tail $=2.306$

Hypothesis 5: Yarn size will impact horizontal and vertical wicking in washed form.

The t-test analysis unveiled that wicking was higher for yarns in medium rather than heavy Yarn size (Table 12). Hypothesis 5 was accepted. Figure 5 reflects so too for yarn size in washed form for both types wicking. None of the previous study discussed this. Therefore, no comparison could be made with prior work.
Hypothesis 6: Satin weave will have higher wicking than the plain and twill weaves due to longer floats in washed form.

Based on ANOVA, this hypothesis was refuted. Plain weave had higher wicking than the satin weave (Table 12). Figure 5 attests so. Further work is needed before generalizing the outcome of this study because conflicting results.

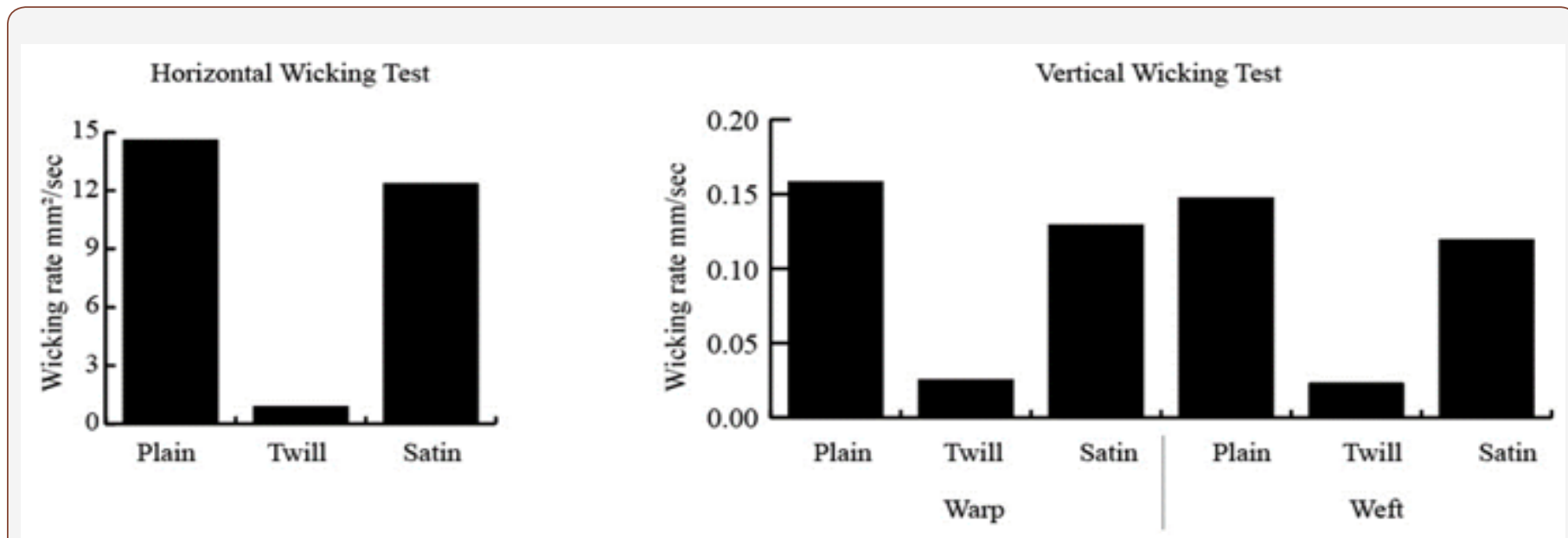

Figure 5: Pictorial depiction of relationship between yarn size as well as three weaves for horizontal and vertical wicking.

Table 12: Comparison of horizontal and vertical wicking by yarn size in washed form.

\begin{tabular}{|c|c|c|c|c|c|c|c|}
\hline \multirow{3}{*}{ Attribute } & \multicolumn{2}{|c|}{ Plain } & \multicolumn{2}{|c|}{ Twill } & \multicolumn{2}{|c|}{ Satin } & \multirow{2}{*}{$\begin{array}{c}\text { F-Value } \\
2,12\end{array}$} \\
\hline & Mean & SD & Mean & SD & Mean & SD & \\
\hline & \multicolumn{2}{|c|}{ Medium } & \multicolumn{2}{|c|}{ Heavy } & \multicolumn{2}{|c|}{ Medium } & \\
\hline Horizontal Wicking & 14.585 & 0.678 & 0.875 & 0.057 & 12.336 & 0.936 & $605.619 *$ \\
\hline \multicolumn{8}{|l|}{ Vertical Wicking } \\
\hline WARP & 0.158 & 0.002 & 0.025 & 0.003 & 0.129 & 0.004 & $2529.828^{*}$ \\
\hline WEFT & 0.147 & 0.003 & 0.023 & 0 & 0.119 & 0.004 & $2537.6^{*}$ \\
\hline
\end{tabular}


Hypothesis 7: Fabric with plied yarns (twill weave) will have lower wicking than the single spun yarns (Plain and Satin weaves).

Twill weave that had plied yarn was compared with plain and satin weaves that had single spun yarns. The t-test analysis that compared twill weave with plain (bleached), plain unbleached and satin weaves. Results revealed that both plain and stain weaves with single spun yarn had significantly higher horizontal wicking than the twill weave. Hypothesis 7 was accepted. Since twill weave involves two twisting operations than plain and satin that were result of one twisting operation. Consequently, twill weave had more crystalline than amorphous region. Amorphous regions are likely to absorb higher moisture than crystalline regions [24]. Therefore, this finding has support from the previous literature $[25,26]$.

Table 13: T-test results for comparison between plain and twill weave, plain and satin weave and satin and twill weave for horizontal wicking in washed form.

\begin{tabular}{|c|c|c|c|c|c|c|}
\hline \multirow{2}{*}{$\begin{array}{c}\text { Dimension \& } \\
\text { Comparison }\end{array}$} & \multicolumn{2}{|c|}{ Plain Bleached } & \multicolumn{2}{c|}{ Twill x Satin } & \multicolumn{2}{c|}{ Satin x Plain } \\
\cline { 2 - 7 } & Twill & Plain B & Twill & Satin & Satin & 12.336 \\
\hline Mean & 0.875 & 26.495 & 0.875 & 0.936 & 0.533 & 0.678 \\
\hline Standard Deviation & 0.057 & 0.533 & 0.057 & & $4.795^{*}$ & \\
\hline t-test & $224.737^{*}$ & & $208.382^{*}$ & & \\
\hline
\end{tabular}

*significant at .05 level: one-tail $=1.86$; two tail $=2.306$

\section{Summary and Conclusion}

To summarize, wicking and moisture transfer were better for washed than unwashed forms for all weaves. Wicking was highest for the plain weave followed by satin and twill weave. Yarn size, yarn type, weave type, thickness, and fabric count. impacted the wicking behavior. Bleached cotton had better wicking than the unbleached cotton. Contrasting findings were found for wicking behavior and water repellency. This study controlled for fiber content and varied for the fabric construction. It also focused on other structural attributes to explain the findings. Analyses included comparisons among and between variables. Though not hypothesized, differences about impact of weight can also be eyeballed through analysis.

\section{Implications for Future}

Due to increased demand for better moisture management, it has become imperative to compare performance of textiles available in the market for its appropriateness for the intended use and compatibility with multiple fiber contents and fabrics used in layered garments [27]. With increased blending of various fiber contents for enhanced comfort and performance makes it more important than ever before to make it their high priority because moisture management also impacts care and comfort. Extending this work to other fiber contents, fabric constructions, fabrics with different types of finishes, and other structural and performance attributes will enhance the reservoir of information base that can benefit future scholars and practitioners in the industry.

Compare garments from various vistas of life to enhance understanding compatibility of textiles for diversified end uses as viable option.

Following questions may serve as the guiding force in accomplishing the proposed goal.

1. What is the role of various fiber contents and finishes with enhancing moisture management capability of textile materials and apparel made thereafter?
2. How layered and unlayered fabrics compare for the wicking behavior and moisture transfer?

3. In which other area can we cross apply the findings from the reported study?

4. What is the relationship between wicking behavior and thermal insulation?

5. How antimicrobial finishes support or challenge comfort, care and durability issues?

6. Should manufacturers consider pre-washing textiles before changing to garments because post-laundering performance was better than the unwashed form?

\section{Acknowledgement}

None.

\section{Conflict of Interest}

No conflict of interest.

\section{References}

1. Nyuni $A B$, Brook D (2006) Wicking mechanisms in yarns - the key to fabric wicking performance. Journal of Textile Institute, 97(2): 119-128.

2. Kundu SK, Chowdhary U (2018) Effect of fiber content on comfort properties of cotton/spandex, rayon/spandex, and polyester/spandex single jersey knitted fabrics. International Journal of Polymer and Textile Engineering 5(3): 33-39.

3. Chatterjee A, Singh P (2014) Studies on wicking behavior of polyester fabric. Journal of Textiles 2014: 1-11.

4. Zhu G, Militky J, Wang Y, Sundarlal BV, Kremenakova D (2015) Study on the Wicking Property of Cotton Fabric. Fibres and Textile in Eastern Europe, Volume 23, 2(110): 137-140.

5. Sengupta AK, Kothari VK, Rangaswamy RS (1991) Wicking behavior of air- jet textured yarns. Indian Journal of Fibre and Textile Research 16: 123-127.

6. Valsang RK, Patil JG (2014) Cotton polyester fabrics wicking behavior. Indian Textile Journal.

7. Parveen BK, Manikari SL (2014) Wicking behavior of woven cotton fabrics by horizontal method. International Journal of Science and Research 3(8): 1147-1151. 
8. Lavate SS, Periyaswamy AP (2014) Wicking behavior of yarn spun from different spinning techniques and their fabrics. Textile Today.

9. Saricum C (2015) Absorption, wicking and drying characteristics of compression garments. Journal of Engineered Fibers and Fabrics 10(3): 146-154.

10. Canan S, Kalaoglue F (2014) Investigation of the wicking and drying behavior of polyester woven fabrics. Fibres and Textile in Eastern Europe 3(105): 73-78.

11. Gorji M, Bagherzadeh R (2016) Moisture management behaviors of high wicking fabrics composed of profiled fabrics. Indian Journal of Fibre and Textile Research 41: 318-324.

12. Riza A, Berkay B (2016) Dendrimer technology for water and oil repellent cotton fabrics. AATCC Journal of Research 3(2): 16-24.

13. Huang KS, Yang KL, Wang SP, Chang YS (2007) Study of the effects of multifunctionality of treating nylon with a mixed sol. The Journal of Textile Institute 98(2): 155-162.

14. Chowdhary U (2017) Comparing three brands of cotton t-shirts. AATCC Journal of Research 4(3): 22-33.

15. Marsha SS, Chowdhary U (2018) Comparison of selected structural and performance attributes of cotton and cotton/polyester blend t-shirts. SSRG Journal of Polymer and Textile Engineering 5(3): 40-49.

16. Telli A, Özdil N (2015) Effect of recycled PET fibers on the performance properties of knitted fabrics. Journal of Engineered Fibers and Fabrics 10(2): 47-60.

17. Uttam D, Sethi R (2016) Impact of repeated washing on dimensional stability and physical factors of cotton woven fabric. International Journal of Research in Engineering and Applied Sciences 6(2): 126-135.
18. Annual Book of ASTM Standards, 7.01. Conshohocken, PA: ASTM International.

19. Technical Manual of the American Association of Textile Chemists and Colorists. Research Triangle park, NC: AATCC.

20. Chowdhary U, Wroblewski SM (2016) Textile analysis: Laboratory manual. Ronkonkoma, NY: LINUS Learning, USA.

21. Chowdhary U (2009) Textile analysis, quality control, and innovative uses. Deer Park, NY: LINUS, USA.

22. Chowdhary U (2007) Textile analysis: Laboratory manual. Deer Park, NY: LINUS, USA.

23. Collier BJ, Epps HH (1999) Textile testing and analysis. Upper Saddle River, NJ: Merrill, USA

24. Johnson I, Cohen AC, Sarkar AK (2015) Fabric science. (11 $1^{\text {th }}$ edn), New York, NY: Bloomsbury, USA.

25. Chowdhary U (2018) Textile analysis: Laboratory manual for online. Ronkonkoma, NY: Linus, USA.

26. Home laundering: Machine washing (2018) AATCC Laundry Procedure. Research Triangle Park, NC American Association of Textile Chemists and Colorists.

27. Chowdhary U, Mathews S (2018) Textile analysis and interpretation for decision making. Trends in Textile Engineering and Fashion Technology $4(1): 1-3$. 